\title{
O TRABALHO DOCENTE NA EDUCAÇÃO INFANTIL EM ESCOLAS RURAIS DE JATAIÍ (GO) ${ }^{1}$
}

\author{
Vânia Ramos Rodrigues ${ }^{2}$ \\ Laís Leni de Oliveira Lima ${ }^{3}$
}

\begin{abstract}
RESUMO Este trabalho é referente uma pesquisa de Mestrado em Educação, o qual, dentre os principais objetivos, tem-se: entender como se tem pensado a constituição do trabalho de professoras para atuar na educação infantil em escolas rurais do município de Jataí (GO). Para o desenvolvimento da pesquisa trabalhamos com levantamento bibliográfico, documental e entrevistas com pessoas em experiências práticas com o problema pesquisado, ou seja, diretoras, professoras e coordenadoras das escolas, por meio de questionários fechados e entrevistas semi-estruturadas. O método científico o qual tem alicerçado esta pesquisa é o materialismo histórico dialético. Nesta perspectiva, entendemos a possibilidade de apreensão do objeto em sua natureza específica, de outro modo estaria encoberto pelo véu das aparências, alienação. Para tanto, embasaremos nosso estudo em aportes teóricos, como: Arce (2004); Arroyo (2007); Marx (1978); Mészáros (2008); dentre outros estudiosos. Dentre os resultados levantados, tem-se: o trabalho que se realiza na em escolas rurais do município de Jataí (GO) não condiz, na maioria dos aspectos, com as propostas definidas pelos Indicadores da Qualidade na Educação Infantil (BRASIL, 2009), dentre elas, estrutura e espaço físico adequado ao atendimento de crianças até 5 anos de idade comprometendo, desse modo, ao desenvolvimento pleno da criança.
\end{abstract}

Palavras-chave: Trabalho docente. Educação infantil. Escola rural.

ABSTRACT This paper is related to a Master's Degree in Education research, which, among the main objectives, is: to understand how it has been thought the constitution of the work of teachers to work in children's education in rural schools in the city of Jataí (GO). For the development of the research we worked with bibliographical, documentary and interviews with people in practical experiences with the researched problem, that is, directors, teachers and coordinators of the schools, through closed questionnaires and semi-structured interviews. The scientific method which has supported this research is dialectical historical materialism. In this perspective, we understand the possibility of apprehension of the object in its specific nature, otherwise it would be veiled by the veil of appearances, alienation. Therefore, we will base our study on theoretical contributions, such as: Arce (2004); Arroyo (2007); Marx (1978); Mészáros (2008); Among other scholars. Among the results obtained, the work carried out in rural schools in the city of Jataí (GO) does not comply, in most aspects, with the proposals defined

\footnotetext{
${ }^{1}$ Tema de pesquisa Mestrado em Educação no Programa de Pós-Graduação em Educação (PPGE) - Universidade Federal de Goiás (UFG)/Regional Jataí no ano de 2016//2017.

${ }^{2}$ Mestranda em Educação - Universidade Federal de Goiás (UFG)/Regional Jataí. Licenciada em Pedagogia UFG/Regional Jataí. Bolsista - Fundação de Amparo à Pesquisa do Estado de Goiás (FAPEG). Contato: vaniaramosr@gmail.com

${ }^{3}$ Doutora em Educação - Universidade Federal de Goiás (UFG)/Goiânia. Docente no Programa de Pós-Graduação em Educação - UFG/Regional Jataí. Docente no curso de Pedagogia - UFG/Regional Jataí. Contato: laisleni@gmail.com
} 
V,13,n.1: 2017

by the Indicators of Quality in Child Education (BRASIL, 2009). Among them, structure and physical space suitable for the care of children up to 5 years of age, thus compromising the full development of the child.

Keywords: Teaching work. Child education. Countryside.

\section{INTRODUÇÃO}

O trabalho que ora se evidencia faz parte de uma pesquisa de Mestrado em Educação, a qual tem como proposta o estudo a respeito da configuração do trabalho de trabalhadores que atuam na área da Educação Infantil, em escolas do meio rural no município de Jataí (GO).

Atualmente, o município de Jataí tem oito escolas no meio rural, as quais ofertam ensino básico desde a educação infantil até o ensino médio. Essas escolas situam-se hoje ao redor do município sendo denominadas de escolas pólo, ou seja, são escolas possuidoras de infraestrutura básica ao atendimento dos alunos, como: salas de aula, secretaria, instalações sanitárias dentre outras; mas que antes, inicialmente, eram mantidas pelos proprietários das fazendas onde a escola era sediada, em diversas regiões do município, com turmas multisseriadas de $1^{\mathrm{a}}$ a $4^{\mathrm{a}}$ série, para atender uma população rural carente em alfabetização. Posteriormente, no final da década de 1980, devido ao funcionamento precário dessas escolas, o prefeito do município regulariza a situação das mesmas por meio do Projeto de Lei municipal $\mathrm{n}^{\mathrm{o}} 1.380 / 89$.

O período de funcionamento dessas escolas, conforme nossa pesquisa é de meio turno, ou seja, na sua maioria no período da manhã. O município oferece transporte escolar tanto aos professores bem como aos alunos que moram distante das escolas.

A educação oferecida às populações rurais do município segue o calendário urbano, por isso as escolas são chamadas de "escolas citadinas". São escolas apenas inseridas no meio rural (LEAL e CARVALHO, 2010).

Para o desenvolvimento da pesquisa, como já mencionado, dentre os principais objetivos temos: entender como se tem pensado a constituição do trabalho de professoras para atuar na educação infantil em escolas da área rural; identificar e compreender como as mediações na formação das trabalhadoras da educação infantil, repercutem no trabalho diário que se realiza com as crianças. 


\section{PERCURSO METODOLÓGICO}

O método científico o qual tem norteado a pesquisa é o materialismo histórico dialético. Esse método foi desenvolvido por Marx, fundamenta-se, inicialmente, na observação da realidade a partir da análise das estruturas e superestruturas que circundam um determinado modo de produção ${ }^{4}$. De acordo com Marx apud Mészaros (2008):

A teoria materialista de que os homens são produto das circunstâncias e da educação e de que, portanto, homens modificados são produto de circunstâncias diferentes e de educação modificada, esquece que as circunstâncias são modificadas precisamente pelos homens e que o próprio educador precisa ser educado. Leva, pois, forçosamente, à divisão da sociedade em duas partes, uma das quais se sobrepõe à sociedade. A coincidência da modificação das circunstâncias e da atividade humana só pode ser apreendida e racionalmente compreendida como prática transformadora (MÉSZAROS, 2008, p. 24 - Grifos do autor).

É uma postura ou compreensão de mundo, no qual contribui para a transformação de uma realidade, ou seja, a práxis.

O método do materialismo histórico-dialético dedica-se ao estudo da natureza, da sociedade humana, considerando as circunstâncias temporais e o contexto histórico em que os homens estão inseridos. Essa historicidade é que determina os fenômenos em constante transformação na vida social, e para serem compreendidos, é necessário então revelar sua situação e suas etapas de modificação, propiciados pela dialética.

Desse modo, pretendemos desenvolver uma pesquisa exploratória, com procedimentos predominantemente qualitativos sem, entretanto, abandonar elementos quantitativos. Segundo Gil (2002, p. 41) a pesquisa exploratória "proporciona maior familiaridade com o problema, com vistas a torná-lo mais explícito [...] tem como objetivo principal o aprimoramento de idéias ou a descoberta de intuições".

Para a coleta de dados na pesquisa, trabalhamos com levantamento bibliográfico, documental, questionários fechados e entrevistas semi-estruturadas com pessoas em experiências práticas com o problema pesquisado (diretoras, coordenadoras e professoras de

\footnotetext{
${ }^{4}$ Segundo a teoria marxista, meios de produção são o conjunto formado por meios de trabalho e objetos de trabalho - ou tudo aquilo que medeia a relação entre o trabalho humano e a natureza, no processo de transformação da própria natureza.
} 
V,13,n.1: 2017

educação infantil). Segundo Lüdke (1986, p. 34), "a grande vantagem da entrevista sobre outras técnicas é que ela permite a captação imediata e corrente da informação desejada". Possibilitando assim aos sujeitos entrevistados em sentirem-se mais a vontade no momento de responder as perguntas.

\section{O TRABALHO DOCENTE NA EDUCAÇÃO INFANTIL}

A Educação Infantil foi incorporada a Educação Básica em 1996 com a Lei de Diretrizes e Bases da Educação Nacional (LDBEN) no 9394/96, juntamente com o Ensino Fundamental e o Ensino Médio, a qual prevê em seu artigo 29:

A educação infantil, primeira etapa da educação básica tem como finalidade o desenvolvimento integral da criança até seis anos de idade, em seus aspectos físico, psicológico, intelectual e social, complementando a ação da família e da comunidade (BRASIL, 1996).

De acordo com a Lei mencionada, em seu Artigo 30, a educação infantil deve ser oferecida em creches para as crianças de 0 a 3 anos, e em pré-escolas para as crianças de 4 e 5 anos. Estabelece também que a educação infantil, como primeira etapa da Educação Básica, é um desafio e que precisa compreender a especificidade educacional da creche, tanto para a proposição de políticas públicas para a organização das práticas cotidianas, quanto às de formação de professores.

Atualmente, a formação inicial do educador para atuação na educação básica, de acordo com a LDBEN no 9394/96 em seu artigo 62:

far-se-á em nível superior, em curso de licenciatura, e graduação plena, em universidades e institutos superiores de educação, admitida, como formação mínima para o exercício do magistério na educação infantil e nas primeiras séries do ensino fundamental, a oferecida em nível médio, na modalidade normal (BRASIL, 1996).

Apesar de a Lei, anteriormente citada, mencionar as exigências de formação do trabalhador na educação básica, bem como as Diretrizes Curriculares para os Cursos de Pedagogia, segundo Vieira (2011), os cursos existentes, muitos deles, estão longe de disponibilizar uma formação de qualidade, uma vez que vários são os caminhos e condições utilizados para este fim. 
V,13,n.1: 2017

A expansão da educação infantil tem ocorrido de forma crescente nas últimas décadas, acompanhando a intensificação da urbanização, a participação da mulher no mercado de trabalho e as mudanças na organização e estrutura das famílias. Por outro lado, a sociedade está caminhando para uma consciência da importância das experiências na primeira infância. Já foi dado um importante passo, onde as instituições pela determinação da $\mathrm{Lei}^{5}$ deixem de ter um caráter assistencialista e passem para instituição "educacional" o que, motiva demandas por uma educação institucional para crianças de zero a cinco anos.

A educação infantil tem uma representação fundamental na sociedade, que confere instruir e capacitar o sujeito ainda em seus primeiros anos de vida, à autonomia, à cidadania. Dado informações normativas a educação infantil, base da educação, tem como propósito formar e construir no sujeito subsídios que cooperem para a convivência em sociedade, desenvolvê-lo nos diferentes aspectos, que favoreçam a formação de maneira integral: capacidades físicas, psíquicas e sociais.

Neste contexto, é salutar destacar aqui a importância da formação do profissional para o trabalho com as crianças pequenas, e que ainda hoje, a implantação de uma educação infantil de qualidade permanece um desafio a ser vencido.

Desde a Lei de Diretrizes e Bases da Educação de 1996 (LDBEN/96) que estabelece a educação infantil como primeira etapa da Educação Básica, é um desafio compreender a especificidade educacional das instituições de educação infantil, tanto para a proposição de políticas públicas, para a organização das práticas cotidianas quanto as de formação de professores.

Em relação à educação da população do meio rural, a LDBEN 9394/96 assim referencia em seu artigo 28:

$\mathrm{Na}$ oferta de educação básica para a população rural, os sistemas de ensino promoverão as adaptações necessárias à sua adequação às peculiaridades da vida rural e de cada região, especialmente:

I - conteúdos curriculares e metodologias apropriadas às reais necessidades e interesses dos alunos da zona rural;

II - organização escolar própria, incluindo adequação do calendário escolar às fases do ciclo agrícola e às condições climáticas;

III - adequação à natureza do trabalho na zona rural (BRASIL, 1996).

\footnotetext{
${ }^{5}$ Lei n ${ }^{\circ} 9.394$ de 20 de dezembro de 1996 (LDBEN - Lei de diretrizes e bases da educação nacional), art. $4^{\circ}$ inciso II com Redação dada pela Lei no 12.796 de 2013. Cf. www.planalto.gov.br.
} 
V,13,n.1: 2017

Considerando as orientações da legislação sobre a adaptação do ensino no meio rural, que atenda às necessidades da comunidade local, verifica-se em estudos como de Caldart (2011); Silva et al. (2010) que a educação do meio rural nada mais é do que a reprodução dos padrões do meio urbano, distanciando das reais necessidades da comunidade rural, com conteúdos e práticas pedagógicas descontextualizadas da localidade.

Em estudos preliminares sobre a educação infantil desenvolvida no campo, constatamos nas pesquisas de Coelho e $\operatorname{Souza}^{6}$ (2011); Gonçalves (2012) a falta de formação específica aos trabalhadores desta área, comprometendo assim a prática educativa desenvolvida em sala de aula, bem como a falta de um currículo contextualizado ao meio rural. São situações, segundo os pesquisadores, resultado de uma política pública que atua na invisibilidade dessa realidade social, provocando assim uma desestrutura física e cultural. Total descaso governamental.

Segundo Coco (2011), apesar de a educação infantil não tenha sido motivo de pauta direta nas legislações educacionais do campo, ela não foi desconsiderada em diferentes discussões empreendidas e, que ao mesmo tempo, é um tema que está em evidência exigindo novas aproximações.

Sob a luz da literatura que aborda sobre a educação rural/campo, deparamos com autores como Arroyo (2007); Arroyo, Caldart e Molina (2004); Ribeiro (2010) dentre outros, os quais, em seus estudos, afirmam sobre a necessidade de as instituições públicas oferecerem cursos específicos de formação aos educadores do campo, equacionando a especificidade da educação dos povos do campo.

Apesar de utilizarmos o termo 'campo' e 'rural' em determinadas passagens do texto, salientamos que existe uma diferença conceitual prática entre os dois termos. O termo 'campo' remete aos conceitos de movimentos sociais, ao campesinato revolucionário. Já o 'rural' referese aos interesses da própria comunidade local, ou seja, da terra. Quando optamos pelo termo da educação 'rural' em nossa pesquisa, foi no entendimento de que "o campesinato subsiste no local como princípio de unidade produtiva familiar" (OLIVEIRA, 2004, p. 65) não possui, portanto, essas características de movimentos sociais.

Assim, partindo do exposto de que a educação no meio rural não atende às necessidades da comunidade local; o considerável número de professores sem formação superior que atuam na educação infantil; as concepções, ainda, assistencialistas que permeiam o fazer docente na educação infantil, um dos motivos, não desconsiderando os demais como: baixos salários,

\footnotetext{
${ }^{6}$ Pesquisa realizada com professoras de EI no meio rural no município de Itaberaba (BA).
} 
V,13,n.1: 2017

maiores jornadas de trabalho, infra-estrutura institucional, dentre outros, que levam a precarização do trabalho docente, o qual subjugado, muitas vezes, aos interesses do capital, a opção foi por pesquisar o professor de educação infantil do meio rural, momento que se interessa saber em quais condições, situações e meios a trabalhadora da educação infantil do meio rural vem se constituindo e, por conseguinte, configurando o seu trabalho.

A seguir apresentamos alguns resultados da pesquisa a qual, se encontra em andamento bem como a análise de dados.

\section{A REALIDADE PESQUISADA}

No decorrer da pesquisa alguns resultados foram levantados, os quais temos condições de demonstrar, tais como a questão do espaço físico ofertado a educação infantil. Constatamos dentre as oito escolas pesquisadas, que somente algumas o ambiente era favorecedor. Fatores diversos contribuíam em sentido contrários as propostas do poder público, tais como: número elevado de crianças por sala; escassez e até falta de material pedagógico destinados às atividades pedagógicas, mobiliário (mesas e cadeiras) inadequado a idade das crianças; salas pequenas, com pouca iluminação e ventilação; ausência de parque infantil; banheiros sem vasos sanitários e lavatórios adequados a altura da criança; dentre outros. Se tomarmos por base o que infere os Indicadores da Qualidade na Educação Infantil, percebe-se que algumas instituições pesquisadas distanciam, e muito, das propostas abaixo:

\footnotetext{
Os ambientes físicos da instituição de educação infantil devem refletir uma concepção de educação e cuidado respeitosa das necessidades de desenvolvimento das crianças, em todos seus aspectos: físico, afetivo, cognitivo, criativo. Espaços internos limpos, bem iluminados e arejados, com visão ampla do exterior, seguros e aconchegantes, revelam a importância conferida às múltiplas necessidades das crianças e dos adultos que com elas trabalham; espaços externos bem cuidados, com jardim e áreas para brincadeiras e jogos, indicam a atenção ao contato com a natureza e à necessidade das crianças de correr, pular, jogar bola, brincar com areia e água, entre outras atividades. O mobiliário deve ser planejado para o tamanho de bebês e de crianças pequenas: é preciso que os adultos reflitam sobre a altura da visão das crianças, sobre sua capacidade de alcançar e usar os diversos materiais, arrumando os espaços de forma a incentivar a autonomia infantil. Os aspectos de segurança e higiene são muito importantes, mas a preocupação com eles não deve impedir as explorações e iniciativas infantis (BRASIL, 2009, p. 50).
} 
V,13,n.1: 2017

São situações, dentre outras, desfavorecedoras ao efetivo trabalho do professor de educação infantil bem como comprometedoras ao próprio desenvolvimento das crianças, como mencionamos anteriormente o artigo 29 da LDBEN nº 9394/96 (BRASIL, 1996).

A falta de formação adequada do trabalhador de educação infantil foi outro fator encontrado em uma instituição no decorrer da pesquisa. Ou seja, em uma das escolas pesquisadas uma trabalhadora na educação infantil não possuía licenciatura em pedagogia. Essa trabalhadora estava na instituição há dois meses, em regime de contrato, substituindo uma servidora efetiva que se encontrava de licença. Uma realidade, segundo Gonçalves (2012), presente na área da educação infantil no meio rural comprometendo, desse modo, o trabalho com as crianças dessa etapa da educação.

\section{CONSIDERAÇÕES}

Entendemos que para o (a) trabalhador (a) da educação infantil possa desenvolver um bom trabalho com as crianças, proporcionando-lhes seu desenvolvimento integral em seus aspectos físico, psicológico, intelectual e social; e promovendo a adequação necessária no caso da educação ofertada no meio rural (BRASIL, 1996), é fundamental que as instituições propiciem condições de trabalho, tanto objetivas quanto subjetivas, que vão de encontro as propostas da educação infantil. Ou seja, infraestrutura e espaços físicos adequados às crianças de até 5 anos de idade; salários dignos aos trabalhadores e condizentes com a carga horária; formação na área que atua.

Consideramos que o objeto investigado é uma realidade viva e está em constante mutação - em devir - assim, nossa reflexão não se esgota, não está pronta, acabada, o que se propõe é senão uma abordagem, um diálogo inicial sobre as realidades de estudo que pretendemos desvelar do decorrer da pesquisa.

\section{REFERÊNCIAS}

ARCE, Alessandra. Pedagogia da infância ou fetichismo da infância? In: DUARTE, Newton (Org.). Crítica ao fetichismo da individualidade. Campinas, SP: Autores Associados, 2004. p. 145-168.

ARROYO, Miguel Gonzalez. Políticas de Formação de educadores (as) do campo. Cad. CEDES, Campinas, v. 27, n. 72, p. 157-176, Ago, 2007. Disponível em: 
REVISTAELETROONICA

H NERAings

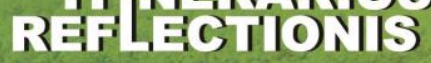

GRADUAÇÃO/PÓS-GRADUAÇAO EM EDUCAÇAO

UFG / REJ

V,13,n.1: 2017

http://www.scielo.br/scielo.php?script=sci_arttext\&pid=S0101-32622007000200004. Acesso em: 1 ago. 2016.

ARROYO, Miguel Gonzalez; CALDART, Roseli; MOLINA, Mônica. Por uma educação do campo. Petrópolis, RJ: Vozes, 2004.

BRASIL. Lei no 9.394/96, de 20 de dezembro de 1996. Lei de Diretrizes e Bases da Educação Nacional. Disponível: 〈http://www.planalto.gov.br/ccivil_03/leis/19394.htm〉. Acesso em 1 abr. 2016.

BRASIL, Indicadores da Qualidade na Educação Infantil. Ministério da Educação/Secretaria da Educação Básica. Brasília: MEC/SEB, 2009.

CALDART, Roseli Salete. Por uma educação do campo: traços de uma identidade em construção. In: ARROYO, Miguel Gonzales; CALDART, Roseli Salete; MOLINA, Mônica Castagna (Org). Por uma educação do campo. 5. ed. Petrópolis: Vozes, 2011. p. 147-158.

COCO, Valdete. Educação Infantil do Campo: aproximações ao cenário do Espírito Santo. Anais da 34 $4^{\mathrm{a}}$ Reunião Anual da Associação Nacional de Pós-graduação e pesquisa em educação. Anped. Educação e Justiça Social. ISSN: 2175-8484. Natal, RN: Anped, 2011.

COELHO, Patrícia Júlia Souza; SOUZA, Elizeu Clementino de. Educação infantil no meio rural de Itaberaba (Bahia): contexto, formação e práticas educativas. Revista Retratos da Escola. Brasília, v. 5, n. 9, p. 341-355, jul./dez. 2011.

GIL, Antônio Carlos. Como elaborar projetos de pesquisa. 4. ed. São Paulo: Atlas, 2002. p. 41-57.

GONÇALVES, Raphaela Dany Freitas Silveira. Educação infantil do campo: entraves e lacunas nas políticas educacionais brasileiras. In: VI COLÓQUIO INTERNACIONAL "EDUCAÇÃO E CONTEMPORANEIDADE". São Cristovão (SE). 20 a 22 de setembro de 2012.

LEAL, Cátia Regina Assis Almeida. CARVAlHO, Tatielle Goulart. Perspectivas de desenvolvimento do Sudoeste Goiano: Repensando a Educação Física Escolar e sua Prática Pedagógica no Contexto da Educação Rural. Jataí, 2010. Relatório Final (PROLICEN) Universidade Federal de Goiás.

LÜDKE, Menga. Pesquisa em educação: abordagens qualitativas. São Paulo: EPU, 1986.

MARX, Karl. Manuscritos econômico-filosóficos e outros textos escolhidos. Seleção de textos de José Arthur Giannoti. Traduções de José Carlos Bruni et al. 2. ed. São Paulo: Abril Cultural, 1978. (Coleção Os pensadores).

MÉSZÁROS, István. A educação para além do capital. (Tradução Isa Tavares). 2. ed. São Paulo: Boitempo, 2008. 
V,13,n.1: 2017

RIBEIRO, Marlene. Movimento camponês, trabalho e educação: liberdade, autonomia, emancipação: princípios/fins da formação humana. 1. ed. São Paulo: Expressão Popular, 2010. $456 \mathrm{p}$.

OLIVEIRA, Breno Louzada Castro de. Educação e ruralidades jataienses. 2004. Dissertação (Mestrado em Educação) - Faculdade de Educação, Universidade Federal de Goiás, Goiânia, 2004.

SILVA. João Paulo dos Santos et.al. Currículo: escola rural Jataiense. In: $7^{\mathrm{a}}$ Semana de Licenciatura, Jataí, GO Jun./2010. Disponível em: <http://www.jatai.ifg.edu.br/semlic/seer/index.php/anais/article/download/74/5>. Acesso em: 20 de abril de 2017.

VIEIRA, Lívia Maria Fraga. Obrigatoriedade escolar na educação infantil. In: Retratos da Escola/ Escola de Formação da Confederação Nacional dos Trabalhadores em Educação (Esforce). v.5, n.9, jul./dez. 2011 - Brasília: CNTE, 2007. 